Saudi Journal of Biomedical Research

Abbreviated Key Title: Saudi J Biomed Res ISSN 2518-3214 (Print) |ISSN 2518-3222 (Online)

\title{
Prevalence and Predictors of Physical Inactivity in a Rural Poulation in Nigeria
}

\author{
Dr. Alikor Chizindu A, Dr. Emem-Chioma Pedro C* \\ Department of Medicine, University of Port Harcourt Nigeria
}

\begin{abstract}
DOI: 1 10.36348/sjbr.2019.v04i11.001 $\quad$ | Received: 02.11.2019| Accepted: 09.11.2019| Published: 14.11 .2019
\end{abstract}
*Corresponding author: Dr. Emem-Chioma Pedro

\section{Abstract}

Introduction: Physical inactivity is a major contributor to the overall burden of cardiovascular disease such as storke, coronary artery diseases and other non-communicable diseases like type 2 diabetes, breast cancer, and colon cancer while Physical activity is a key and important factor that contributes to decrease the risk of cardiovascular disease. The aim of this study is to determine the prevalence and predictors of physical inactivity in a rural population in Nigeria. Methods: A cross sectional rural population study involving 572 subjects aged 15 years and above. Socio-demographic data were obtained by face-to-face interview. Weight, height, waist circumference, hip circumference measurements were taken along with blood pressure measurements. Blood samples were taken for fasting blood sugar and lipid profile. Results: Five Hundred and seventy two had their data analysed with male to female ratio of 1:2.6. The overall mean age was $39.08 \pm 17.5$ years. The overall prevalence of physical inactivity in this study was $3 \%$ to $7.3 \%$ during commuting or working respectively with men being more active than females. The elderly age group of 70 years and above were more sedentary than all other age groups. Pearson correlation and Spearman' rho correlation analyses showed that smoking and BMI correlated with obesity. Linear regression analysis showed that smoking and BMI predicted presence of physical inactivity. Conclusion: Physical inactivity prevalence in this study is low with smoking and BMI being important predictors.

Keywords: Prevalence, Predictors, physical inactivity, rural, population.

Copyright @ 2019: This is an open-access article distributed under the terms of the Creative Commons Attribution license which permits unrestricted
use, distribution, and reproduction in any medium for non-commercial use (NonCommercial, or CC-BY-NC) provided the original author and source
are credited.

\section{INTRODUCTION}

Physical inactivity is a major contributor to the overall burden of cardiovascular disease such as stroke, coronary artery diseases and other non-communicable diseases like type 2 diabetes, breast cancer, and colon cancer [1-3]. Physical activity therefore is a key and important factor that contributes to decrease the risk of cardiovascular disease [4]. Adequate physical activity involves aerobic use of large muscle groups at about $60 \%$ functional capacity for at least twice weekly for 90 minutes per week or engaging in at least 30 minutes of modest activity on most, preferably all days of the week. Modest activity is defined as any activity that is similar in intensity to brisk walking at a rate of about 3 to 4 miles per hour [5]. The activities can include any other form of occupational or recreational activity that is dynamic in nature and of similar intensity, such as cycling, yard work, household tasks, and swimming.

Overweight and obesity are major contributors to overall NCD associated mortalities [6]. World Health Organisation (WHO) in a bid to taming the menace of obesity and physical inactivity with an understanding of the health benefits of regular physical activity passed resolution WHA55.23 in 2002 [6-8] with subsequent development of appropriate steps aimed at tackling the issue of physical activity and health [9]. There is increasing rate of sedentary lifestyle among young people and even children with epidemiologic transition going on in sub-Saharan Africa. This concept of 'physical activity transition' is becoming endemic with its attendant complications especially in the 'westernised' cities and towns [10-14]. A work done about 15 years ago in Kenya among young students of 13 to 15 years showed a troubling high prevalence $(40.9 \%)$ of sedentary habits [15] Muthoni Gichu et.al recently reported a prevalence of $7.7 \%$ in their study of the prevalence and predictors of physical inactivity levels among Kenyan adults[16]. Muthoni et al. further established that Physical inactivity was associated with female gender, middle age (30-49 years), and increasing level of education, increasing wealth index and low levels of High Density Lipoproteins (HDL) [16]. 
Work done by some Nigerian authors has shown prevalence rates of physical inactivity to be in the range of reported that 25-57\% [17]. Babatunde et al. in their survey of physical Inactivity in Nigerian Young Adults got a prevalence of $41 \%$ with higher prevalence rate found among women than men [18]. The Harvard alumni study showed an inverse relation between level of physical activity and the risk of premature death In the Harvard study, the most active men had about $50 \%$ the risk of death of the least active [4]. Leisure-time physical activity is also found to significantly reduce the risk of cardiovascular mortality [19]. A rise in the rate of physical activity has been found to be associated with a reduction in waist: hip ratio and a higher HDL-cholesterol in women [20]. It was also shown that increase physical activity was inversely associated with body mass index and percentage fat [21].

In Nigeria, most of the published works on physical inactivity level are mainly urban based with scarce resources on the rural pattern of physical inactivity. This study therefore is to determine the prevalence and predicators of physical inactivity among adult population of a rural community which may be of importance in policy formulations as even the rural Nigerian communities gradually undergo epidemiologic transition.

\section{METHODOLOGY}

This is a cross sectional study involving five hundred and seventy two adults in a rural community of the Etche-speaking tribe of Rivers state in the Niger Delta region of Nigeria.

\section{OCCUPATION}

The vast majority of the study population are involved in non-mechanised farming with cassava, maize, okro, pumpkin vegetable as their commonly planted crops. Non-agricultural workers are mainly teachers in the primary and secondary schools in the community and neighbourhood. Many women engage in petty trading but this is mainly limited to selling the farm products.

\section{Questionnaire preparation and administration}

The questionnaire which was designed to elicit socio-demographic data including age, gender, occupation, educational level, cigarette smoking, and alcohol consumption was administered by face-to-face interview. Physical activity was assessed with World Health Organization (WHO) Step questionnaire which was modified to fit into the activities peculiar to the rural community where this study was done. The activities were categorised into occupational, commuting and recreational. Level of physical activities were categorised into vigorous-intensity activities (which included activities that cause large increases in breathing or heart rate, sweating such as carrying or lifting heavy loads, digging or construction work, farming manually, chopping fire wood, wrestling etc.); moderate-intensity activities (which included activities that cause small increases in breathing or heart rate such as brisk walking, pounding, cycling, dancing etc) and sedentary activities(included sitting or reclining for most work time, storytelling, watching television, travelling most times by motor bike, car, bus etc).

\section{Anthropometric, Blood Pressure Measrement and Blood Sample Collection}

Anthropometric and blood pressure measurements were done according to standard practice [22]. Participant's heights were measured without foot wear and headdress to the nearest $0.1 \mathrm{~cm}$ and their weight taken to the nearest $0.1 \mathrm{~kg}$. Waist circumference was measured midway between the uppermost border of the iliac crest and the lower border of the costal margin (rib cage). Hip circumference was measured in a horizontal plane at the maximum width over the greater trochanter. Fasting blood sample was taken for both blood glucose and lipid analyses consistent with standard protocol [23-26].

\section{Ethical consideration}

Consent from the village Chiefs/Community and religious leaders were obtained. Consent from each study participant was also obtained for the study. Approval of the Ethics committee of the University of Port Harcourt Teaching hospital was obtained.

\section{STATISTICAL ANALYSIS}

Statistical analysis was done using Statistical Package for Social Sciences (SPSS Inc, Chicago, IL) version 17. Results were expressed as either mean values (standard deviation) or proportions. Comparison for statistical significance was by student's t test for Continuous variables and chi-square analysis for categorical variables. Epi info statistical package version 3.5.1 was used for chi-square for trend analysis. Pearson and Spearman' rho correlation test were used to determine the relationship between obesity and its possible risk factors. Logistic regression was also done. A p-value of $\leq 0.05$ was considered statistically significant.

\section{Definition of terminologies}

For the purpose of this study, definition of terminologies was made;

1. Physical inactivity is defined as:

$\mathrm{i}$ Activity at work or leisure that is not vigorous or moderate in intensity for at least 10 minutes continuously for $\geq 3$ days in a week OR

ii Not commuting by foot or use of bicycle (cycling) for at least 10 minutes continuously for $\geq 3$ days in a week.

BMI was calculated as weight $(\mathrm{kg}) /$ height $\left(\mathrm{m}^{2}\right)$ [27].

Under weight- $<18.5 \mathrm{Kg} / \mathrm{m}^{2}$

Normal Weight- 18.5 to $24.9 \mathrm{Kg} / \mathrm{m}^{2}$

Overweight- 25 to $29.9 \mathrm{Kg} / \mathrm{m}^{2}$ 
Obesity- > $30 \mathrm{Kg} / \mathrm{m}^{2}$

\section{Waist Circumference}

Normal- $<102 \mathrm{~cm}$ for males, $<88 \mathrm{~cm}$ for females Abnormal- $\geq 102 \mathrm{~cm}$ for males, $\geq 88 \mathrm{~cm}$ for females

\section{Waist-hip-ratio}

Normal $-<1$ for males, $<0.9$ for females

Abnormal $\geq 1$ for males, $\geq 0.9$ for females

Hypertension was defined using the JNC 7 (Joint National Committee on Prevention, Evaluation, and Treatment report) criteria of blood pressure $\geq$ $140 / 90 \mathrm{mmHg}$ or self-reported antihypertensive medication use [28].
Diabetes mellitus was defined using fasting plasma glucose $(\mathrm{FPG}) \geq 7.0 \mathrm{mmol} / 1(126 \mathrm{mg} / \mathrm{dl})$ and individuals who were previously known to have diabetes based on history of drug medication were also classified to have diabetes.

Total cholesterol of $>6 \mathrm{mmol} / \mathrm{L}, \mathrm{TG}>$ $1.8 \mathrm{mmol} / \mathrm{L}, \quad \mathrm{HDL}-\mathrm{C}<1.0 \mathrm{mmol} / \mathrm{L}$ and $\mathrm{LDL}-\mathrm{C} \geq$ $3 \mathrm{mmol} / \mathrm{L}$ were taken as abnormal values.

\section{RESULTS}

Five Hundred and seventy two had their data analysed with male to female ratio of $1: 2.6$. The overall mean age was $39.08 \pm 17.5$ years. Table I shows age and sex distribution of the study group.

Table-I: Age and sex distribution of study group

\begin{tabular}{|l|l|l|l|l|l|l|}
\hline \multirow{2}{*}{ Age group ( years) } & \multicolumn{2}{|l|}{ OVERALL } & MALES & \multicolumn{2}{l|}{ FEMALES } \\
\cline { 2 - 7 } & Number & $\mathbf{\%}$ & Number & $\mathbf{\%}$ & Number & \% \\
\hline $18-29$ & 222 & 38.8 & 51 & 31.9 & 171 & 41.5 \\
$30-39$ & 74 & 13.0 & 22 & 13.8 & 52 & 12.6 \\
$40-49$ & 106 & 18.5 & 32 & 20.0 & 74 & 18.0 \\
$50-59$ & 74 & 13.0 & 19 & 11.9 & 55 & 13.3 \\
$60-69$ & 66 & 11.5 & 21 & 13.1 & 45 & 11.0 \\
70 and above & 30 & 5.2 & 15 & 9.3 & 25 & 3.6 \\
\hline Total & $\mathbf{5 7 2}$ & $\mathbf{1 0 0}$ & $\mathbf{1 6 0}$ & $\mathbf{2 8 . 0}$ & $\mathbf{4 1 2}$ & $\mathbf{7 2 . 0}$ \\
\hline
\end{tabular}

Physical activity history - Table II shows that less than $10 \%$ of the study group were sedentary at work with most persons commuting by foot or use of bicycle. The overall prevalence of physical inactivity in this study was $3 \%$ to $7.3 \%$ during commuting or working respectively with men being more active than females. The elderly age group of 70 years and above were more sedentary than all other age groups.

Table-II: Prevalence of physical inactivity

\begin{tabular}{|l|l|l|l|}
\hline \multirow{2}{*}{ Variable } & \multicolumn{3}{|c|}{ Physical inactivity } \\
\cline { 2 - 4 } & $\begin{array}{c}\text { At work } \\
\text { \% }\end{array}$ & $\begin{array}{c}\text { Commuting } \\
\text { \% }\end{array}$ & $\begin{array}{c}\text { During recreation } \\
\mathbf{\%}\end{array}$ \\
\hline Males & & & \\
18-29 years & 0 & 0 & 5.9 \\
30-39 years & 0 & 0 & 22.7 \\
40-49 years & 0 & 0 & 31.3 \\
50-59 years & 0 & 0 & 63.2 \\
60-69 years & 14.3 & 4.8 & 90.5 \\
$\geq 70$ years & 40.0 & 33.3 & 100 \\
\hline Total & $\mathbf{6 . 6}$ & $\mathbf{3 . 7}$ & $\mathbf{4 3 . 1}$ \\
\hline Females & & & \\
18-29 years & 0 & 0 & 30.9 \\
30-39 years & 0 & 0 & 57.7 \\
40-49 years & 0 & 0 & 74.3 \\
50-59 years & 0 & 0 & 90.9 \\
60-69 years & 6.7 & 2.2 & 100 \\
$\geq 70$ years & 33.3 & 32.0 & 100 \\
\hline Total & $\mathbf{8 . 0}$ & $\mathbf{2 . 7}$ & $\mathbf{6 2 . 6}$ \\
\hline Overall prevalence & $\mathbf{7 . 3}$ & $\mathbf{3 . 0}$ & $\mathbf{5 7 . 2}$ \\
\hline
\end{tabular}

Table-III: Gender differences in the means of systolic and diastolic blood pressure.

\begin{tabular}{|l|l|l|l|l|l|l|l|}
\hline \multirow{2}{*}{ VARIABLES } & \multicolumn{2}{l|}{ TOTAL } & \multicolumn{2}{l|}{ MALES } & \multicolumn{2}{l|}{ FEMALES } & P $*$ \\
\cline { 2 - 8 } & $\mathrm{n}$ & Mean \pm SD & $\mathrm{n}$ & Mean \pm SD & $\mathrm{n}$ & Mean \pm SD & value \\
\hline SBP $(\mathrm{mmHg})$ & 550 & $120.04 \pm 21.40$ & 160 & $123.54 \pm 19.50$ & 390 & $118.59 \pm 21.9$ & 0.013 \\
DBP $(\mathrm{mmHg})$ & 550 & $73.64 \pm 12.50$ & 160 & $75.88 \pm 12.80$ & 390 & $72.72 \pm 12.30$ & 0.007 \\
\hline
\end{tabular}

$\mathrm{SBP}=$ systolic blood pressure; $\mathrm{DBP}=$ diastolic blood pressure; $\mathrm{n}=$ number. $\mathrm{P}^{*}=$ Significant. 
Table-IV: Relationship of physical inactivity with risk factors for physical inactivity

\begin{tabular}{|l|l|l|}
\hline VARIABLES & COEFFICIENT OF CORRELATION(r) & P value \\
\hline Smoking & -0.098 & 0.05 \\
BMI & -0.100 & 0.02 \\
\hline
\end{tabular}

Table-V: Regression analysis of physical inactivity and correlates

\begin{tabular}{|l|l|l|l|l|}
\hline VARIABLES & B & STANDARD ERROR & WALD & P value \\
\hline Smoking & -0.759 & 0.39 & 3.88 & 0.04 \\
BMI & -0.789 & 0.316 & 6.25 & 0.012 \\
\hline
\end{tabular}

Pearson correlation and Spearman' rho correlation analyses (Table IV) showed that smoking and BMI correlated with obesity. Linear regression analysis, (Table V), showed that smoking and BMI predicted presence of physical inactivity.

\section{DISCUSSION}

The prevalence of physical inactivity in this study especially among the young and middle aged group is low similar to the documentations of Muthoni et al. in Kenya where a prevalence of $7.7 \%$ was reported [16]. It is however lower than the work of other authors both in Nigeria and the African continent [15, 17-18]. Physical activities were attributed to occupational and commuting than leisure activities similar to the findings by Forrest et.al in Benin City, Nigeria [17]. These comparative Nigerian studies were however urban studies among various professional groups who spend most of the work hours sitting and commute around mostly by vehicles. The findings of low prevalence of sedentary lifestyle in this study is not surprising as a large proportion of the study subjects were farmers who engage in active physical work including daily trekking to the farm, market, church etc.

In this study however, there was an increasing physical inactivity level with increasing age and the elderly age group of 70 years and above were more sedentary than all other age groups unlike the Benin study where no significant trend was observed across age groups. In this study, physical inactivity was found to be higher in women than men similar to the findings in other local and international studies $[15,17,18,29$ 34].

A rise in the rate of physical activity has been found to be associated with a reduction in waist:hip ratio and a higher HDL-cholesterol in women [20]. It has also been shown by previous authors that increase in physical activity was inversely associated with body mass index and percentage fat [21]. This agrees with the finding of this present study showing low prevalence of abdominal obesity with greater percentage of the participants having normal body weight similar to the work of Okesina and colleagues in rural Maiduguri [35]. In the Benin City study, physical activity, especially time walking or biking to work, was inversely correlated with weight, BMI, WHR, blood pressures, insulin, total cholesterol, LDL and HDL cholesterol, and triglycerides in men, while such correlations were not consistent in women. In multivariate analysis in men, an independent inverse association was seen between walking and BMI [17]. This finding in our study is unlike the Akpa el.al study in urban city of Port Harcourt with higher prevalence rate [36]. The difference may be partly related to the fact that whereas this present study is a rural study, the Akpa et al study was done in an urban, industrialised city of Port Harcourt with increasing rate of westernisation of lifestyle.

This inverse relationship between generalised obesity and high physical activities found in this study is linked to the occupation and other activities of this rural community such farming and household chores like pounding, chopping of fire woods including wrestling as a recreational activity.

In this study BMI and smoking were reported as predictors of physical inactivity. Both weight gain and weight loss are functions of energy balance, and prevention of weight gain can theoretically be achieved by changes in both dietary energy balance and physical activity [37-38].

\section{REFERENCES}

1. World Health Organization. (2009). Global health risks: mortality and burden of disease attributable to selected major risks. Geneva: World Health Organization.

http://www.who.int/healthinfo/global_burden_dise ase/global_health_risks/en/.

2. Lee, I. M., Shiroma, E. J., Lobelo, F., Puska, P., Blair, S. N., Katzmarzyk, P. T., \& Lancet Physical Activity Series Working Group. (2012). Effect of physical inactivity on major non-communicable diseases worldwide: an analysis of burden of disease and life expectancy. The lancet, 380(9838), 219-229.

3. Kyu, H. H., Bachman, V. F., Alexander, L. T., Mumford, J. E., Afshin, A., Estep, K., \& Cercy, K. (2016). Physical activity and risk of breast cancer, colon cancer, diabetes, ischemic heart disease, and ischemic stroke events: systematic review and dose-response meta-analysis for the Global Burden of Disease Study 2013. bmj, 354, i3857.

4. Paffenbarger Jr, R. S., Hyde, R. T., Wing, A. L., Lee, I. M., Jung, D. L., \& Kampert, J. B. (1993). The association of changes in physical-activity level and other lifestyle characteristics with 
mortality among men. New England journal of medicine, 328(8), 538-545.

5. United States. Public Health Service. Office of the Surgeon General, National Center for Chronic Disease Prevention, Health Promotion (US), President's Council on Physical Fitness, \& Sports (US). (1996). Physical activity and health: A report of the Surgeon General. US Department of Health and Human Services, Centers for Disease Control and Prevention, National Center for Chronic Disease Prevention and Health Promotion.

6. World Health Organization. (2014). Global status report on noncommunicable diseases 2014 (No. WHO/NMH/NVI/15.1). World Health Organization.

7. Physical Activity Guidelines Advisory Committee. (2018). Physical activity guidelines advisory committee scientific report. Washington, DC: US Department of Health and Human Services, 2018, F2-33.

8. World Health Organisation.(2002). WHA 55.23

2002 resolution: WHO; 2002. Available http://apps.who.int/gb/archive/pdf_files/WHA55/e wha5523. pdf?ua $=1$.

9. WHO. (2004). Global strategy on diet, physical activity and health. Geneva: WHO. Available: http://apps.who.int/iris/bitstream/handle/10665/430 35/ 9241592222_eng.pdf? sequence $=1$.

10. Katzmarzyk, P. T., \& Mason, C. (2009). The physical activity transition. Journal of Physical activity and Health, 6(3), 269-280.

11. Omram, A. R. (1983). The epidemiologic transition theory. A preliminary update. Journal of tropical pediatrics, 29(6), 305-16.

12. Wang, Y., \& Lim, H. (2012). The global childhood obesity epidemic and the association between socio-economic status and childhood obesity.

13. Hill, J. O., \& Wyatt, H. R. (2005). Role of physical activity in preventing and treating obesity. Journal of Applied Physiology, 99(2), 765-770.

14. Abarca-Gómez, L., Abdeen, Z. A., Hamid, Z. A., Abu-Rmeileh, N. M., Acosta-Cazares, B., Acuin, C., ... \& Agyemang, C. (2017). Worldwide trends in body-mass index, underweight, overweight, and obesity from 1975 to 2016: a pooled analysis of 2416 population-based measurement studies in 128. 9 million children, adolescents, and adults. The Lancet, 390(10113), 2627-2642.

15. World Health Organization, \& Centers for Disease Control and Prevention (CDC. (2013). Global school-based student health survey (GSHS).

16. Gichu, M., Asiki, G., Juma, P., Kibachio, J., Kyobutungi, C., \& Ogola, E. (2018). Prevalence and predictors of physical inactivity levels among Kenyan adults (18-69 years): an analysis of STEPS survey 2015. BMC public health, 18(3), 1217.

17. Forrest, K. Y., Bunker, C. H., Kriska, A. M., Ukoli, F. A., Huston, S. L., \& Markovic, N. I. N. A. (2001). Physical activity and cardiovascular risk factors in a developing population. Medicine and Science in Sports and Exercise, 33(9), 1598-1604.

18. Adegoke, B. O., \& Oyeyemi, A. L. (2011). Physical inactivity in Nigerian young adults: prevalence and socio-demographic correlates. Journal of physical activity and Health, 8(8), 1135-1142.

19. Slattery, M. L., Jacobs Jr, D. R., \& Nichaman, M. Z. (1989). Leisure time physical activity and coronary heart disease death. The US Railroad Study. Circulation, 79(2), 304-311.

20. Heim, D. L., Holcomb, C. A., \& Loughin, T. M. (2000). Exercise mitigates the association of abdominal obesity with high-density lipoprotein cholesterol in premenopausal women: results from the third National Health and Nutrition Examination Survey. Journal of the American Dietetic Association, 100(11), 1347-1353.

21. Pate, R. R., Pratt, M., Blair, S. N., Haskell, W. L., Macera, C. A., Bouchard, C., \& Kriska, A. (1995). Physical activity and public health: a recommendation from the Centers for Disease Control and Prevention and the American College of Sports Medicine. Jama, 273(5), 402-407.

22. Marks, L. A., \& Groch, A. (2000). Optimizing cuff width for noninvasive measurement of blood pressure. Blood pressure monitoring, 5(3), 153158.

23. Trinder, P. (1969). Determination of blood glucose using 4-amino phenazone as oxygen acceptor. Journal of clinical pathology, 22(2), 246.

24. Tietz, N.W.(1990). Clinical Guide to Laboratory Tests, Second Edition W.B Saunders Company, Philadelphia, USA 554-556.

25. Friedewald, W. T., Levy, R. I., \& Fredrickson, D. S. (1972). Estimation of the concentration of lowdensity lipoprotein cholesterol in plasma, without use of the preparative ultracentrifuge. Clinical chemistry, 18(6), 499-502.

26. Tietz, N.W.(1990). Clinical Guide to Laboratory Tests, Second Edition W.B Saunders Company, Philadelphia, USA 554-556.

27. Eknoyan, G. (2007). Adolphe Quetelet (17961874) - the average man and indices of obesity.

28. Joint, National. (1993). Committee on Detection, Evaluation, and Treatment of High Blood Pressure (JNC-7). The seventh report of the Joint National Committee. Arch Intern Med 1993; 153: 154-83.

29. Bauman, A., Bull, F., Chey, T., Craig, C. L., Ainsworth, B. E., Sallis, J. F., ... \& Pratt, M. (2009). The international prevalence study on physical activity: results from 20 countries. International journal of behavioral nutrition and physical activity, 6(1), 21.

30. Guthold, R., Ono, T., Strong, K. L., Chatterji, S., \& Morabia, A. (2008). Worldwide variability in physical inactivity: a 51-country survey. American journal of preventive medicine, 34(6), 486-494.

31. Gal, D. L., Santos, A. C., \& Barros, H. (2005). Leisure-time versus full-day energy expenditure: a 
cross-sectional study of sedentarism in a Portuguese urban population. BMC public health, 5(1), 16.

32. Al-Tannir, M., Kobrosly, S., Itani, T., El-Rajab, M., \& Tannir, S. (2009). Prevalence of physical activity among Lebanese adults: a cross-sectional study. Journal of Physical Activity and Health, 6(3), 315-320.

33. Bergman, P., Grjibovski, A. M., Hagströmer, M., Bauman, A., \& Sjöström, M. (2008). Adherence to physical activity recommendations and the influence of socio-demographic correlates-a population-based cross-sectional study. BMC Public Health, 8(1), 367.

34. Trin, O. T. H., Nguyen, N. D., Dibley, M. J., Phongsavan, P., \& Bauman, A. C. (2008). The prevalence of physical inactivity among adults in Ho Chi Minth city. BMC Public Health, 8, 204.
35. Okesina, A. B., Oparinde, D. P., Akindoyin, K. A., \& Erasmus, R. T. (1999). Prevalence of some risk factors of coronary heart disease in a rural Nigerian population. East African medical journal,76(4), 212-216.

36. Akpa, M. R., Emem-Chioma, P. C., \& Odia, O. J. (2008). Current epidemiology of hypertension in Port Harcourt metropolis, Rivers state, Nigeria. Port Harcourt Medical Journal, 2(3), 218223.

37. Misra, A., \& Khurana, L. (2008). Obesity and the metabolic syndrome in developing countries. The Journal of Clinical Endocrinology \& Metabolism, 93(11_supplement_1), s9-s30.

38. Fogelholm, M., \& Kukkonen-Harjula, K. (2000). Does physical activity prevent weight gain-a systematic review? Obesity reviews, 1(2), 95-111. 